E. G. Pringsheim discusses the interesting problems of apochlorosis, J. Hämmerling recent work on the nuclearcytoplasmic relationships in Acetabularia, and H. Gaffron photochemical aspects of the beginnings of life.

The entire work bears testimony, if that were needed, to the vigorous modern developments in many branches of phycology. It can be recommended to all interested in algae, as a stimulating survey of recent work in this biological group.

A. Alisope

\section{NATURALLY OCCURRING OXYGEN RING COMPOUNDS}

\section{Naturally Occurring Oxygen Ring Compounds}

By Dr. F. M. Dean. Pp. viii +661. (London: Butterworth and Co. (Publishers), Ltd., 1963.) $120 s$.

A $\mathrm{T}$ the present time there is a large and wide variety of text-books dealing with the various aspects and branches of organic chemistry, but only a few make any mention of the naturally occurring oxygen ring compounds. Brief accounts of these are found in text-books of general organic and heterocyclic chemistry, when only $a_{a}$ few selected examples are given of naturally occurring oxygen ring compounds, in order to round off a chapter on a particular oxygen heterocyclic ring system. This deficiency of material dealing with naturally occurring oxygen ring compounds in the general chemical literature suitable for students and research workers is rather remarkable in view of the fact that the study of the oxygen heterocyclic constituents of plants has developed concurrently with organic chemistry, and that it now makes an important and distinctive contribution to other studies, such as genetics, agriculture and medicine. Naturally Occurring Oxygen Ring Compounds, which is probably the first to attempt to treat the whole of the chemistry of the naturally occurring oxygen ring compounds, is certainly very welcome.

Some chapter titles are based on the parent ring systems, furans, benzofurans, coumarins, etc., as is common in the majority of text-books of heterocyclic chemistry. After a general introduction to the topic, these chapters follow a set pattern and continue with an outline of the fundamental chemistry of the parent ring system, but not so fully as in some modern text-books of heterocyclic chemistry, which in their part neglect the chemistry of related naturally occurring compounds. The chapters are concluded by an extensive account of the chemistry of numerous related naturally occurring compounds, giving the method by which their structure was elucidated and, where applicable, the synthesis of the compound. In all cases, adequate reference is given to the original literature and any interesting observations are given worthy note and brought to the attention of the reader. Efforts have been made at least to mention topics other than purely chemical ones. Other chapter titles are those of groups of naturally occurring compounds, the anthocyanins, catechins, etc.: again in these chapters topics are mentioned other than those of a purely chemical nature which may be of interest to some readers, for example, in autumn when leaves have lost their chlorophyll, the presence of the anthocyanins together with carotenes, accounts for the varied and beautiful colours, characteristics of that season. The isolation of the products and elucidation of their structure are described from a historical approach, but in all cases a full account is given of modern methods, including the use of physical chemical techniques. In fact, these chapters in all deal with the structural chemistry of some hundreds of natural products, as elucidated by more than eighty years of intensive study.

One of the later chapters deals with less common ring systems, the others having dealt with five- and six- membered rings containing one oxygen atom, and which are generally entitled oxygen ring compounds. Three-, four- and seven-membered rings are not numerous, nor are rings containing more than one oxygen atom. The chief groups discussed are the 1,2-epoxides, the importance of which has not long been appreciated, and the depsidones, which have been well known for many years and contain seven-membered rings with two oxygen atoms. Some epoxides are found among the alkaloids, while the occurrence of others in the fungal metabolites, especially the macrolides, is now an established feature. Many of the simpler epoxides can be recognized by standard methods, especially acid-catalysed hydration to the corresponding glycols followed by periodic acid fission.

The last chapter of the book is devoted to the subject of biosynthesis, and the author relates that in the previous seventeen chapters two larger allied problems have had to wait for proper attention; namely, how such products are constructed by organisms, and the function, if any, served by them. The biosynthetical point of view is concerned in the main with the construction and modification of carbon chains and rings, so the discussion in this chapter must frequently cut across the usual classification into pyrones, furans, etc., and include compounds that are not heterocyclic. Again the author treats this topic with his usual thoroughness, starting with an interesting introduction and survey of the investigations carried out in recent years followed by numerous examples, always giving ample credit to the efforts of the main workers in this field.

The appendix to the book contains some of the important material published in 1961, which could not be incorporated in the text at the time of writing. There is no doubt that Dr. F. M. Dean has put a great deal of thought and work into producing this excellent book, which is a very valuable addition to the chemical literature, and will without doubt find a place in all chemical libraries. It will be of great value to all research workers carrying out investigations in the oxygen heterocyclic field. I can find only praise for the general set-out of the book, the excellent diagrams and the inclusion of more than two thousand references covering the period up to 1961 .

R. LIVINGStone

\section{ORGANIC CHEMISTRY FOR BIOCHEMISTS}

\section{Comprehensive Biochemistry}

Vol. 9: Pyrrole Pigments, Isoprenoid Compounds and Phenolic Plant Constituents. Pp. xiv + 265. 70s. Vol. 10: Sterols, Bile Acids and Steroids. Pp. xii +209. 55s. Edited by Marcel Florkin and Elmer H. Stotz. (Amsterdam, London and New York: Elsevier Publishing Company, 1963.)

TN the general preface, the editors state that "the 1 middle three sections, Chemistry of Biological Compounds, Biochemical Reaction Mechanisms, and Metabolism, may be considered classical biochemistry". The editors' plan to include a great deal of pure chemistry, although it probably resulted in the elevation of not a few academic eyebrows, is a realistic appraisal of the scope of modern biochemistry. Reading this treatise is obviously going to be a tough, intellectual marathon; the task will nevertheless be rewarding for all who wish to keep the biochemical front line in sight rather than allow it to disappear beyond the horizon.

Volume 9 is subdivided into three fairly distinct sections. In the first, J. E. Falk describes the chemistry and biochemistry of porphyrins and metalloporphyrins, while J. N. Phillips gives a complementary account of their physicochemical properties. There is no attempt to 